\title{
Microwave Ablation Using Four-Tine Antenna: Effects of Blood Flow Velocity, Vessel Location, and Total Displacement on Porous Hepatic Cancer Tissue
}

\author{
Montree Chaichanyut and Supan Tungjitkusolmun \\ Department of Electronic Engineering, Faculty of Engineering, King Mongkut's Institute of Technology Ladkrabang, \\ Bangkok 10520, Thailand
}

Correspondence should be addressed to Supan Tungjitkusolmun; ktsupan@gmail.com

Received 11 March 2016; Revised 12 May 2016; Accepted 30 June 2016

Academic Editor: Enrique Berjano

Copyright (C) 2016 M. Chaichanyut and S. Tungjitkusolmun. This is an open access article distributed under the Creative Commons Attribution License, which permits unrestricted use, distribution, and reproduction in any medium, provided the original work is properly cited.

\begin{abstract}
This research is concerned with microwave ablation analyses using a $2.45 \mathrm{GHz}$ four-tine (4T) antenna for hepatic cancer tissue. In the study, three-dimensional finite-element models were utilized to examine the tissue temperature distributions during and after MW ablation. A preliminary study was first carried out with regard to the specific absorption rates along the $4 \mathrm{~T}$ antenna insertion depths and the temperature distributions inside the solid and porous liver models with either $3 \mathrm{~cm}$-in-diameter tumor or $5 \mathrm{~cm}$-indiameter tumor. Based on the preliminary results, the porous models were further examined for the effect of varying blood flow velocities $(0-200 \mathrm{~cm} / \mathrm{s})$ with a $1 \mathrm{~cm}$-in-diameter blood vessel next to the antenna and also for the effect of vessel-antenna locations $(0,0.8$, and $1.3 \mathrm{~cm})$ with a constant blood flow velocity of $16.7 \mathrm{~cm} / \mathrm{s}$. All scenarios were simulated under temperature-controlled mode $\left(90^{\circ} \mathrm{C}\right)$. The findings revealed that the blood flow velocity and vessel location influence the ablation effectiveness and that increased blood flow inhibits heat transfer to the vessel wall. At the nearest and farthest vessel-antenna locations $(0$ and $1.3 \mathrm{~cm})$, approximately $90.3 \%$ and $99.55 \%$ of the cancer cells were eradicated except for the areas adjacent to the vessel. In addition, total tissue thermal displacement is $5.9 \mathrm{~mm}$ which is $6.59 \%$ of the total length of the overall model.
\end{abstract}

\section{Introduction}

Theoretically, microwave (MW) ablation possesses a number of advantages over the conventional radiofrequency $(\mathrm{RF})$ ablation technique. In RF ablation $(300 \mathrm{kHz}-1 \mathrm{MHz})$, Joule heating is mainly generated by conduction current, while both conduction and displacement currents cause tissue temperatures to increase in MW ablation (generally at $915 \mathrm{MHz}$ or $2.45 \mathrm{GHz}$ ) [1].

The conventional RF ablation method has proved effective in treatment of liver cancer with diameter of less than $3 \mathrm{~cm}[2,3]$ but is afflicted with increased tissue impedance and the subsequent tissue boiling and charring [4]. In other words, the zone of active tissue treated with RF ablation is limited to a few millimeters surrounding an active electrode [5]. The majority of tissue heating is thus due to thermal conduction, which decreases exponentially away from the source. RF heating requires an electrical conduction path while MW is capable of propagating through material with low or zero conductivity (or high impedance) [6].

For cancer treatment with MW ablation, a thin antenna is inserted into a tumor through either open surgery or laparoscopy or percutaneously to deposit an electromagnetic (EM) field on the cancer tissue. Heating is induced using the conductive and displacement currents to affect the coagulative necrosis of tumor cells upon the temperatures reaching $50^{\circ} \mathrm{C}$ or above. The MW ablation zone characteristics (e.g., size and shape) are primarily subject to the antenna design [7-20]. Typically, an MW antenna is fed with a coaxial cable, whose topology and feed structure are optimized to achieve the intended heating pattern while choking the currents that flow on the outer surface of the outer conductor of the feeding coaxial cable. Examples of existing MW antennas are the monopole antenna [7-11], dipole or floating sleeve 


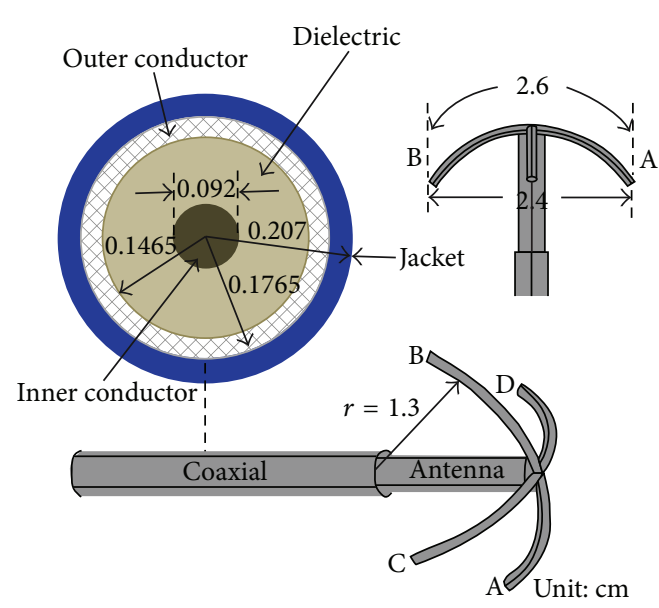

(a) $4 \mathrm{~T}$ antenna

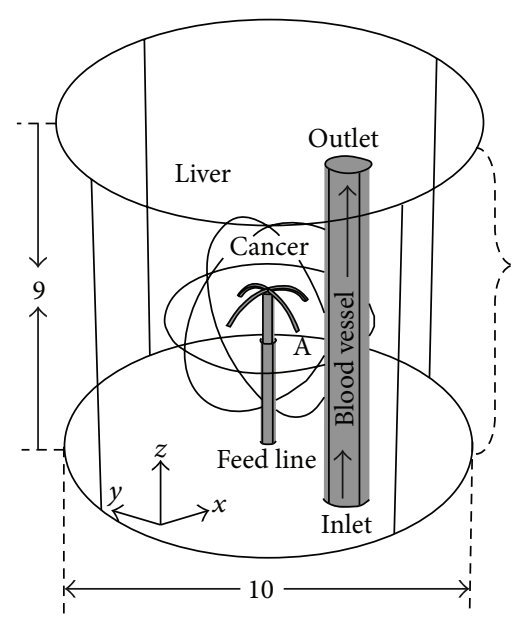

(b) Analysis model

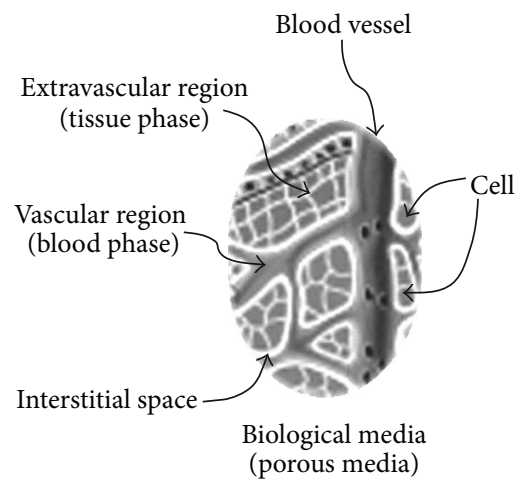

(c) Biological porous media

FIGURE 1: FEM model for liver ablation using the $4 \mathrm{~T}$ antenna. The $4 \mathrm{~T}$ antenna is fully deployed in the liver and a single $1 \mathrm{~cm}$ blood vessel is located $1.3 \mathrm{~cm}$ to the right of point $\mathrm{A}$ (four-tine $(\mathrm{A}, \mathrm{B}, \mathrm{C}$, and $\mathrm{D})$ ).

dipole antenna $[7-9,12,13]$, choke or cap-choke antenna $[7,8,12,13]$, triaxial antenna $[10,16]$, metal tip monopole antenna [6], open tip monopole antenna [11, 17], and an open slot and multislot antennas [18-20]. These aforementioned antennas are most appropriate for teardrop-shaped tumors. In addition, tumors could develop near a blood vessel or cystic masses, thereby impeding the propagation of MW fields and thermal distribution.

In [21-24], the authors have documented the advantages of simultaneous activation of multiple antennas for achieving large ablative zones. The utilization of multiantenna systems requires determining the optimal antenna spacing for realization of the maximum ablative zone without indentations, since the presence of such indentations indicates incomplete destruction of the targeted tumor. To address the multiantenna's indentation issue, this current research thus presents a novel four-tine (4T) MW antenna that could potentially elevate tissue temperatures of large area without indentations (Figure 1(a)). In the antenna design, the inner conductor of a monopole antenna is connected to four conducting tines in an umbrella-like array arrangement similar to the four-tine RF probe in $[2,25,26]$. The $4 \mathrm{~T}$ MW antenna is placed inside a penetrating sleeve prior to introducing into the cancerous liver tissue. Once the sleeve is properly lodged inside the tumor, the $4 \mathrm{~T}$ array can be fully deployed as illustrated in Figures 1(a)-1(b).

Most previous researches on MW ablation for hepatic cancer regarded the liver tissue as a homogeneous solid mass and also focused exclusively on heat conduction within the tissue. Pennes's bioheat equation describes thermal conduction in the tissue and vascular system, blood perfusion, and metabolic heat generation [13-19].

Biological tissue comprises three components: blood vessels, cells, and interstitial space. In addition, biological media can be categorized as the vascular region (blood vessels) and extravascular region (cells and the interstitial space). Thus, the anatomical structure of the liver can be represented more accurately as a blood-saturated porous tissue [2729], in which the vascular region is regarded as a blood phase and the extravascular region is regarded as a tissue phase (solid matrix), as illustrated in Figure 1(c). When the temperature of biological tissue rises, its shape is deformed due to thermal strain $[30,31]$. Nevertheless, the majority of existing studies on MW ablation for hepatic cancer have focused predominantly on the EM wave propagation and heat transfer and also failed to explore the issue of mechanical tissue deformation.

This research has investigated the specific absorption rates (SARs) in the liver tissue using a $2.4 \mathrm{~cm}$ diameter $4 \mathrm{~T}$ antenna (upon fully deployed). The temperature distributions of the solid and porous liver tissue models during and after MW ablation were examined and compared. In addition, the effects of blood flow velocity and vessel location on the temperature distributions in the liver tissue were determined. The total displacements of the porous liver tissue model during and after MW ablation were also investigated.

\section{Materials and Methods}

2.1. Mathematical Descriptions of the Simulation Models. Figure 2 depicts a block diagram of the mathematical analysis pertinent to this research whose constituents encompass the $\mathrm{EM}$, heat transfer, fluid flow, and mechanical changes analyses in MW ablation. The descriptions of each analysis are as follows.

EM Wave Propagation Analysis. The EM wave propagation in the liver tissue is rendered in a 3D model and calculated using Maxwell's equations. The general form of Maxwell's equations for transverse electromagnetic wave (TEM) mode is derived assuming a harmonic propagation and is simplified to demonstrate the EM field in a biological medium $[32,33]$.

Fluid Flow Analysis. This research utilized the incompressible Navier-Stokes (N-S) model to simulate the laminar flow 


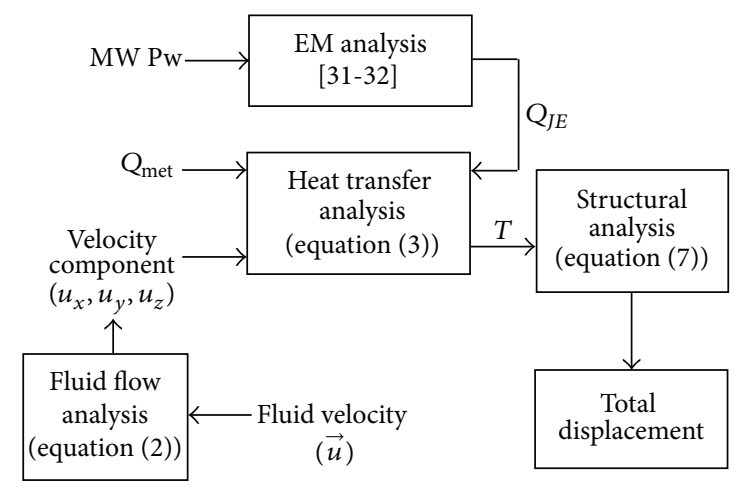

Figure 2: Block diagram of the mathematical analysis relevant to this research.

conditions inside a blood vessel [34]. The general form of the $\mathrm{N}$-S equation is valid for the flow inside the pores of a porous medium. Vafai and Tien [35] studied the heat transfer in porous media and proposed a modified momentum equation as follows:

$$
\rho_{\mathrm{bl}}(\langle\vec{u}\rangle \cdot \nabla)\langle\vec{u}\rangle=-\nabla\langle P\rangle+\mu_{\mathrm{bl}} \nabla^{2}\langle\vec{u}\rangle-\frac{\mu_{\mathrm{bl}}}{K} \phi\langle\vec{u}\rangle,
$$

where the subscript "bl" denotes blood and applies to an incompressible fluid (blood) of density $\rho_{\mathrm{bl}}\left(\mathrm{kg} / \mathrm{m}^{3}\right),\langle\vec{u}\rangle=$ $\left(u_{x}, u_{y}, u_{z}\right)$ is the average blood velocity $(\mathrm{mm} / \mathrm{s}),\langle P\rangle$ is the average fluid (blood) pressure $(\mathrm{Pa})$, and $\mu_{\mathrm{bl}}$ is the dynamic viscosity of blood (Pa.s). The dynamic viscosity of blood was $3.5 \times 10^{-3} \mathrm{~Pa} \cdot \mathrm{s} ; K$ and $\phi$ are, respectively, the permeability $\left(\mathrm{m}^{2}\right)$ and the porosity of the porous liver tissue.

This research assumes a simple steady flow of incompressible fluids in which the inertia term $\rho_{\mathrm{bl}}(\langle\vec{u}\rangle \cdot \nabla)\langle\vec{u}\rangle$ in (1) is neglected. The Navier-Stokes equation is thus reduced to the Brinkman equation given as follows [36]:

$$
0=-\nabla\langle P\rangle+\mu_{\mathrm{bl}} \nabla^{2}\langle\vec{u}\rangle-\frac{\mu_{f}}{K} \phi\langle\vec{u}\rangle .
$$

Heat Transfer Analysis. The thermal distribution within the porous liver is obtained by solving the energy equations of tissue and blood phases, in which the absorbed MW power and an internal heat source (i.e., metabolic heat source) are included. In addition, this research assumes that the tissue and blood temperatures are identical (local thermal equilibrium (LTE)) [37].

According to [38], Pennes's bioheat equation fails to account for the effect of directional blood flow on heat transfer. To model the thermal energy propagation through the tissue and vessel from the ablation zone, this research utilized a convection-conduction Klinger model with the assumption of quasi-steady state as follows:

$$
\begin{gathered}
\left(\rho c_{p}\right)_{\mathrm{ts}} \frac{\partial T_{\mathrm{ts}}}{\partial t}+\phi\left(\rho c_{p}\right)_{\mathrm{bl}}(\langle\vec{u}\rangle \cdot \nabla T) \\
=\nabla \cdot\left(k_{\mathrm{ts}} \nabla T_{\mathrm{ts}}\right)+Q_{\mathrm{met}}+Q_{J E},
\end{gathered}
$$

where the subscripts "ts" and "bl," respectively, denote the tissue and blood phases. $T$ is the temperature $\left({ }^{\circ} \mathrm{C}\right) ; \rho$ is the density $\left(\mathrm{kg} / \mathrm{m}^{3}\right) ; c_{p}$ is the specific heat capacity $\left(\mathrm{J} / \mathrm{kg} .{ }^{\circ} \mathrm{C}\right) ; k$ is the thermal conductivity $\left(\mathrm{W} / \mathrm{m} \cdot{ }^{\circ} \mathrm{C}\right) ; \phi$ is the porosity which is the ratio of the blood volume to the total volume [27]. The metabolic heat generation rate of $33800 \mathrm{~W} / \mathrm{m}^{3}$ was used [39] and the external heat source was equal to the resistive heat generated by the EM field $\left(Q_{J E}=J \cdot E\left(\mathrm{~W} / \mathrm{m}^{3}\right)\right)$.

Structural Analysis. Heat transfer analysis provides us with the temperature at each element in the simulated model. A change in the temperature of a material contributes to variation in the material's overall size as a result of thermal strain [30, 31]. Temperature change could thus induce the dimension or shape variations in the liver tissue. In this research, it is assumed that the liver tissue is homogeneous and isotropic, and the strain $(\varepsilon)$ consists of thermal $\left(\varepsilon_{\mathrm{th}}\right)$, elastic $\left(\varepsilon_{\mathrm{el}}\right)$, and initial $\left(\varepsilon_{0}\right)$ contributions such that

$$
\varepsilon=\left(\varepsilon_{\mathrm{th}}\right)+\left(\varepsilon_{\mathrm{el}}\right)+\left(\varepsilon_{0}\right) .
$$

To simplify the analysis and investigate the effect of thermal strain on the liver tissue, this research disregards the mechanical strain $\left(\varepsilon_{\mathrm{el}}\right)$. The linear relationship between the thermal strain-induced deformation and temperature change is expressed as

$$
\varepsilon_{\mathrm{th}}=\alpha\left(T-T_{\mathrm{ref}}\right),
$$

where $\alpha$ is the thermal expansion coefficient $\left(1 /{ }^{\circ} \mathrm{C}\right)$ and $T_{\text {ref }}$ is the reference temperature $\left({ }^{\circ} \mathrm{C}\right)$.

Let us consider a small section (element) of the overall model as a small and finite cuboid in the Cartesian coordinates $(\{x, y, z\})$ and the dimensions of each side of the cuboid in initially undeformed state are, respectively, $\Delta x, \Delta y$, and $\Delta z$. Due to the thermal strain, the cuboid is deformed, with displacement components in $x, y$, and $z$ directions denoted by displacement vector $D_{i} \equiv\left(D_{x i}, D_{y i}, D_{z i}\right)$, where the subscript " $i$ " is the index of the element. The deformed cuboid still remains a cuboid as shear strains are assumed to be zero throughout so that the angles are preserved. The dimensions of the cuboid sides nevertheless change, respectively, to $\Delta x_{i}+$ $\Delta D_{x i}, \Delta y_{i}+\Delta D_{y i}$, and $\Delta z_{i}+\Delta D_{z i}$, where $\Delta D_{x i}, \Delta D_{y i}$, and $\Delta D_{z i}$ denote the appropriate displacement increments.

Each component of the thermal strain depends on the displacements in each axis. Under the assumption of small displacements, the displacement vector $\left(D_{x i}, D_{y i}, D_{z i}\right)$ can be calculated from the thermal strain components $\left(\varepsilon_{x x i}, \varepsilon_{y y i}, \varepsilon_{z z i}\right)$ as follows [40]:

$$
\begin{aligned}
& \varepsilon_{x x i}=\frac{\partial D_{x i}}{\partial x} \\
& \varepsilon_{y y i}=\frac{\partial D_{y i}}{\partial y} \\
& \varepsilon_{z z i}=\frac{\partial D_{z i}}{\partial z}
\end{aligned}
$$

Therefore, the total displacement (TD) of the model is

$$
\mathrm{TD}=\sqrt{\sum_{i}\left(\operatorname{real}\left(D_{i}\right)\right)^{2}} .
$$


TABLE 1: Dimensions of model components.

\begin{tabular}{lcc}
\hline \multirow{2}{*}{ Components } & \multicolumn{2}{c}{ Dimensions } \\
& Length $(\mathrm{cm})$ & Diameter $(\mathrm{cm})$ \\
\hline Inner conductor & 4.2 & 0.092 \\
Dielectric & 4.2 & 0.293 \\
Outer conductor & 2.9 & 0.353 \\
Antenna, four-tine antenna & 1.3 & 0.092 \\
(A, B, C, and D) & 9.0 & 1.0 \\
Blood vessel & - & 5.0 \\
Tissue (cancer) & 9.0 & 10.0 \\
Tissue (liver) & & \\
\hline
\end{tabular}

2.2. Properties of the Antenna. The four-tine array could be made from the shape-memory alloys (Ni-Ti alloy) with sharp edges and the $4 \mathrm{~T}$ antenna was encapsulated in a guiding sleeve during insertion (Figures 1(a)-1(b)). Once the $4 \mathrm{~T}$ antenna was placed at the target location, we pushed the $4 \mathrm{~T}$ antenna forward into the liver to enable the four-tine array to penetrate into tissue. Once the four-tine array was fully deployed, the guiding sleeve was withdrawn from the liver.

2.3. Experimental Validation Setup. In order to validate the computational results from this study, we built a prototype 4T antenna based upon the results of the optimization and then tested this device in egg white and in swine liver. MW ablation was performed with input power of $50 \mathrm{~W}$ for a duration of $900 \mathrm{~s}$. The power inputs were constantly varied to maintain the maximum temperature of $90^{\circ} \mathrm{C}$. The thermocouple was placed $0.5 \mathrm{~cm}$ from the distal end of the antenna to measure temperature and was used as feedback to control power to maintain the maximum temperature of $90^{\circ} \mathrm{C}$. Measurements were performed by inserting $4 \mathrm{~T}$ antenna in $250 \mathrm{~cm}^{3}$ egg white and in $10 \mathrm{~cm} \times 10 \mathrm{~cm}$ freshly excised swine liver obtained from a local slaughterhouse.

The prototype $4 \mathrm{~T}$ antenna was constructed with the same dimensions as the model using a Multiflex 141 Coaxial Cable (Micro-Coax, Huber+ Suhner AG. RF Industrial, Herisau, Switzerland). The entire outer and the inner conductors are made from silver-plated copper wire. The coaxial dielectric used is a low-loss polytetrafuoroethylene (PTFE). Dimensions of the coaxial cable used to build the antenna assembly are provided in Table 1 .

2.4. Analysis Assumptions. This research investigates the phenomenon within solid and porous biological media during and after MW ablation. With reference to Figure 1(c), in which the biological medium is porous, this research is carried out based upon the following assumptions:

(i) The outer surface of the porous liver is truncated by a scattering boundary condition (waves could pass through boundary without reflection) and the propagation of EM wave is confined to the liver tissue.

(ii) The porous liver tissue is homogenous, thermally isotropic, and blood-saturated [41]. (iii) Neither phase changes within the porous liver nor energy exchange through the outer surface of the porous liver takes place [42].

(iv) The porosities and thermal properties of the porous liver are assumed to be constant [43].

(v) The initial temperature within the liver tissue is assumed to be uniform $\left(37^{\circ} \mathrm{C}\right)$.

2.5. Comparison of Non-Blood Vessel Solid and Porous Models. In the finite-element (FE) analyses of the non-blood vessel models, the proposed $4 \mathrm{~T}$ antenna was situated at the center of the liver. The antenna was first inserted from the tumor base along $z$-axis until the antenna tip was $0.7 \mathrm{~cm}$ above the center of the spherical tumor. Figure 1(b) illustrates the FE analyses for both the solid and porous liver tissue models. The overall FE models are of cylindrical shape (diameter = $10 \mathrm{~cm}$ and length $=9 \mathrm{~cm}$ ) with spherical hepatic cancer tissue of either $3 \mathrm{~cm}$ or $5 \mathrm{~cm}$ in diameter.

The boundary conditions and material properties were assigned prior to solving the thermal-electrical problems. In the MW ablation, the initial power was set at $50 \mathrm{~W}$ and the maximum temperature was monitored. Upon the hepatic cancer tissue temperature reaching $90^{\circ} \mathrm{C}$, the power inputs were constantly varied to maintain the maximum temperature of $90^{\circ} \mathrm{C}$. We limited the maximum temperature to $90^{\circ} \mathrm{C}$ to avoid situation where water in tissue reached boiling point which will cause bubbles. Similar temperature limit has also been used in other studies [24]. We selected the temperature-controlled mode, since it is more widely used in clinical practice to help reduce the incidence of overheating of the catheter-tissue interface and coagulation.

In addition, comparisons were made between the specific absorption rates (SARs) of the solid and porous models and between their temperature distributions.

2.6. Effects of Blood Flow Velocity. In this research, an extreme case was simulated in which a $1 \mathrm{~cm}$-in-diameter blood vessel was deliberately placed in immediate contact with point A and the hepatic cancer size was $5 \mathrm{~cm}$ in diameter (Figure 3 ). The blood flow velocity was varied between $0 \mathrm{~cm} / \mathrm{s}$ and $200 \mathrm{~cm} / \mathrm{s}$ to investigate the effect of blood flow on the temperature distribution and lesion formation during and after MW ablation. The variations in blood flow velocity range from $0 \mathrm{~cm} / \mathrm{s}, 0.1 \mathrm{~cm} / \mathrm{s}, 0.5 \mathrm{~cm} / \mathrm{s}, 1 \mathrm{~cm} / \mathrm{s}, 5 \mathrm{~cm} / \mathrm{s}, 10 \mathrm{~cm} / \mathrm{s}$, $15 \mathrm{~cm} / \mathrm{s}, 15.8 \mathrm{~cm} / \mathrm{s}, 16.7 \mathrm{~cm} / \mathrm{s}, 19.4 \mathrm{~cm} / \mathrm{s}, 50 \mathrm{~cm} / \mathrm{s}, 100 \mathrm{~cm} / \mathrm{s}$, and $200 \mathrm{~cm} / \mathrm{s}$.

\subsection{Effect of Blood Vessel Location on Lesion Formation and} Tissue Deformation. To determine the effect of blood vessel location on the temperature distribution, the distances of the $1 \mathrm{~cm}$-in-diameter blood vessel from point $\mathrm{A}$ (i.e., one of the distal ends of the $4 \mathrm{~T}$ antenna) in the $5 \mathrm{~cm}$-in-diameter hepatic cancer porous model were varied between $0,0.8$, and $1.3 \mathrm{~cm}$, as illustrated in Figure 3. The 3D FE analyses were thus performed for the following cases.

Case 1. The blood vessel was in immediate contact $(0 \mathrm{~cm})$ with point $\mathrm{A}$ and parallel to the $4 \mathrm{~T}$ antenna. 

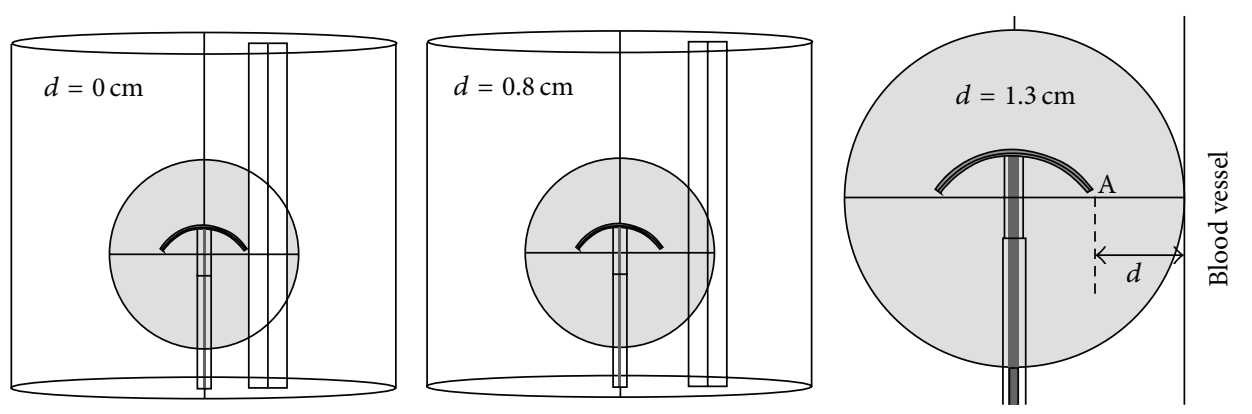

FIGURE 3: FEM model for liver ablation using the 4T MW antenna. The antenna is fully deployed in the liver and the antenna-vessel locations are $0,0.8$, and $1.3 \mathrm{~cm}$ to the right of point $\mathrm{A}$ (i.e., one of the distal ends of the $4 \mathrm{~T}$ antenna).

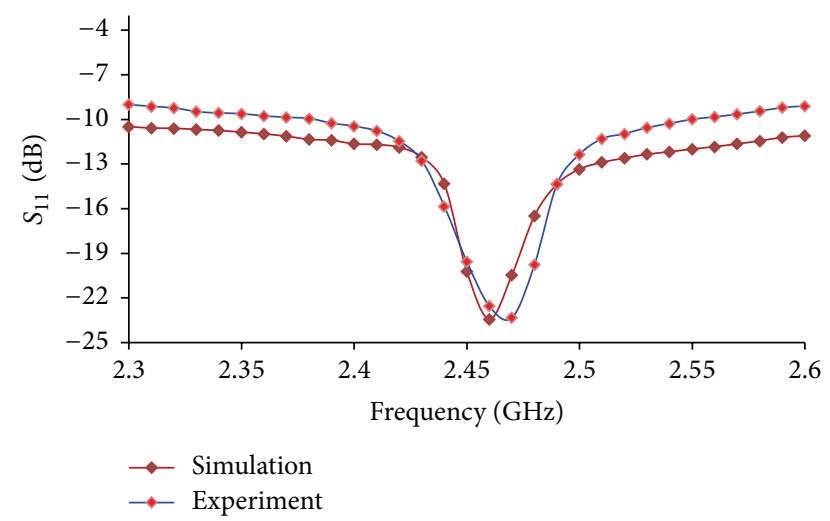

FIGURE 4: Frequency response of $4 \mathrm{~T}$ antenna $\left(S_{11}\right)$.

Case 2. The blood vessel was $0.8 \mathrm{~cm}$ from point $\mathrm{A}$ and parallel to the $4 \mathrm{~T}$ antenna. The blood vessel center was situated at the outer edge of the hepatic cancer.

Case 3. The blood vessel was $1.3 \mathrm{~cm}$ from point $\mathrm{A}$ and parallel to the $4 \mathrm{~T}$ antenna. The blood vessel's outer wall was in contact with the hepatic cancer's outer edge.

Similar to Section 2.4 and Section 2.5, the boundary conditions and material properties were established prior to solving the thermal-electric-fluid-structural problems, except for the blood flow velocity which was assumed to be constant at $16.7 \mathrm{~cm} / \mathrm{s}$ [44]. Comparisons were made with regard to the temperature distributions between the three distances to determine the effect of the location of blood vessel on the lesion formation.

2.8. Material Properties. Tables 1 and 2, respectively, tabulate dimensions and the properties of the proposed microwave antenna components, tissue and blood vessel, used in the FE models [15, 20, 25, 45-48]. All conductors of $4 \mathrm{~T}$ antennas are assumed to be perfect electric conductors (PEC).

2.9. Meshing. A Cauchy convergence test was performed to determine appropriate mesh sizes for the simulated models and the threshold for maximum temperature difference was set at $0.1^{\circ} \mathrm{C}$ [49]. The mesh of all the liver tissue models was finer at the areas surrounding the four distal ends of the antenna (minimum grid size of $0.001 \mathrm{~cm}$ ) and was coarser at locations farther away from the antenna tip (maximum grid size of $1 \mathrm{~cm}$ ). The overall solid and porous FE models were of cylindrical shape $(10 \mathrm{~cm}$ in diameter and $9 \mathrm{~cm}$ in length) with approximately 420000 tetrahedral elements individually.

2.10. Software. Since the antenna geometry is complex, the numerical modeling was utilized to perform the 3D FE analyses to obtain the temperature distributions during and after MW ablation. The FE models were analyzed using COMSOL Multiphysics 5.1 (COMSOL, Inc., Burlington, MA) run on a PC with $3.60 \mathrm{GHz}$ Intel ${ }^{\circledR}$ Pentium CORE $^{\mathrm{TM}}$ i7-3820 CPU, $24 \mathrm{~GB}$ of RAM, and $1 \mathrm{~TB}$ of hard disk space. The simulations performed with COMSOL Multiphysics included the RF module, heat transfer (bioheat equation) module, fluid flow module, and structure-mechanics module.

\section{Research Results}

Upon the establishment of the geometrical model, the FE mesh, and the material properties and boundary conditions, the FE analyses were carried out and postprocessing was performed for the simulation results as below.

3.1. Properties of the $4 T$ Antenna. We measured $S_{11}$ of the $4 \mathrm{~T}$ antenna in the range of 2.0 to $2.6 \mathrm{GHz}$ in a $50 \mathrm{MHz}$ step to characterize the frequency response of the antenna. We tested the fabricated prototype by measuring $S_{11}$ using the Bird Site Analyzer Model SA-6000 EX (Bird Electronic Corporation, Cleveland, $\mathrm{OH}$ ). Figure 4 illustrates simulated $S_{11}$ amplitude of $4 \mathrm{~T}$ antenna versus those from experimental measurements. $S_{11}$ at $2.45 \mathrm{GHz}$ from the simulation result and experimental measurements were $-20.21 \mathrm{~dB}$ and $-19.56 \mathrm{~dB}$, respectively. The discrepancies in $S_{11}$ between FE simulations and the in vitro study was approximately $3.33 \%$.

3.2. Results from In Vitro Experiments. Figures 5(a) and 5(b) show ablation zones after $900 \mathrm{~s}$ in egg white $(5.6 \mathrm{~cm} \times$ $5.05 \mathrm{~cm})$ and in swine liver $(4.85 \mathrm{~cm} \times 4.15 \mathrm{~cm})$, respectively. We compared the results from in vitro experiments and FE simulation of porous tissue model (no blood vessel) in Section 3.3. 


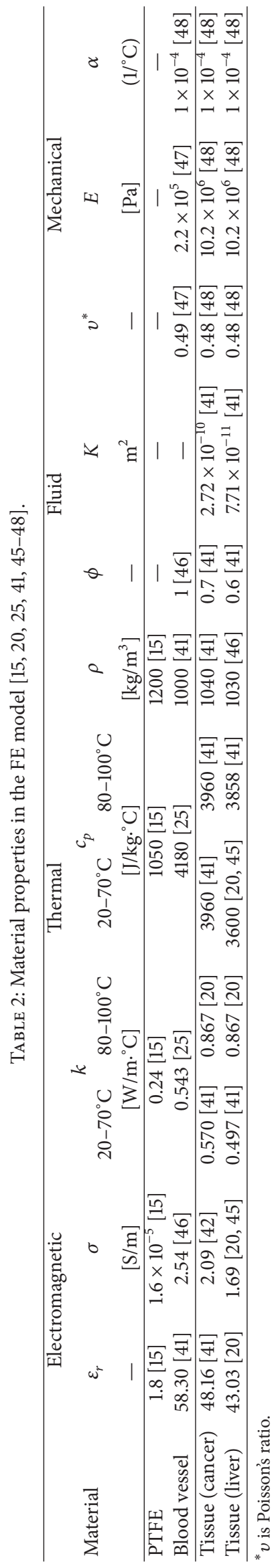




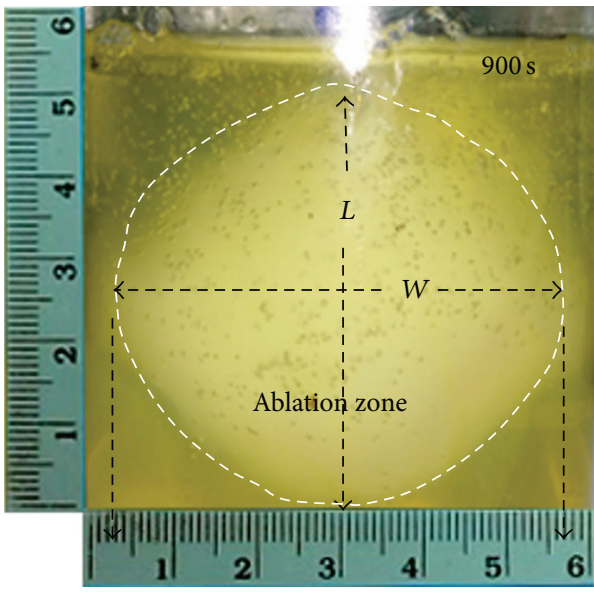

(a) Egg white

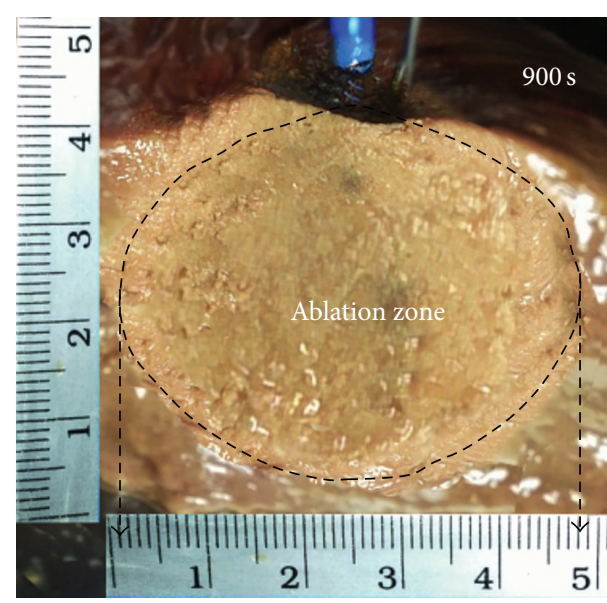

(b) Swine liver

FIGURE 5: Ablation zones created in in vitro experiments at the end of a $900 \mathrm{~s}$ MWA procedure (egg white, $5.6 \mathrm{~cm} \times 5.05 \mathrm{~cm}$, and swine liver, $4.85 \mathrm{~cm} \times 4.15 \mathrm{~cm}($ size $=W \times L))$.

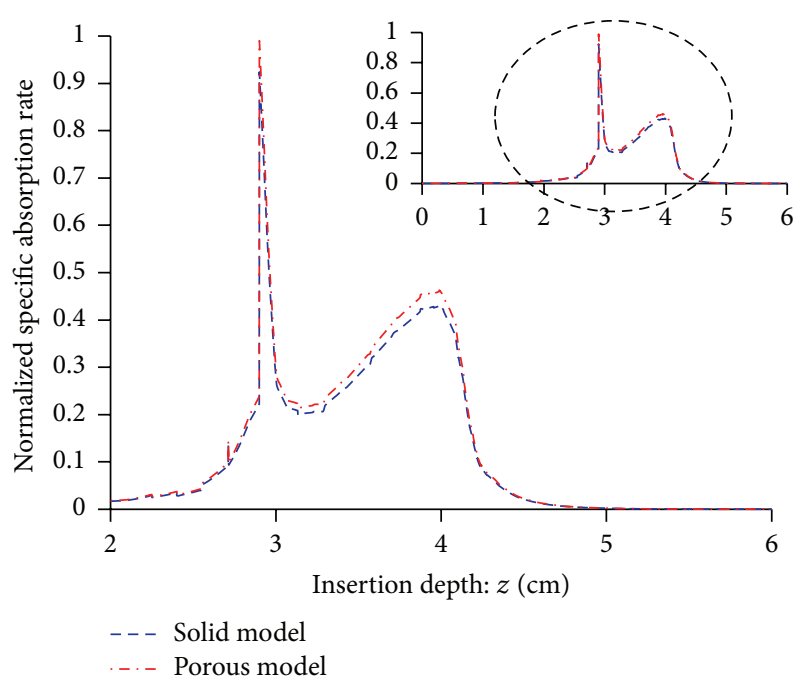

FIGURE 6: SAR along the insertion depths of $4 \mathrm{~T}$ antenna.

\subsection{Comparison of the Solid and Porous Models}

SAR Distributions. Figure 6 illustrates the specific absorption rates relative to the antenna insertion depths $(z=0-0.6 \mathrm{~cm})$ from the FE analyses of the solid and porous liver tissue models, respectively. The SARs along $z$-axis at $0.125 \mathrm{~cm}$ radius were normalized. The local peaks of the SAR curves for both solid and porous models occurred at the interface between the distal end of the monopole antenna and the four tines (i.e., points A, B, C, and D), as seen in Figure 1(a). The SAR profile curves of the solid and porous models exhibited similar trends with slightly different amplitudes.

Temperature and Power Observations. Figures 7(a)-7(b), respectively, depict the MW power delivery and the resulting maximum temperatures relative to time from the FE analyses of the solid and porous liver tissue models. The MW power delivery was varied to maintain the target temperature of $90 \pm 1^{\circ} \mathrm{C}$. Initially, the tissue temperature rose rapidly to $90^{\circ} \mathrm{C}$ in $12 \mathrm{~s}$ and $35 \mathrm{~s}$, respectively, for the solid and porous models with a $50 \mathrm{~W}$ power delivery which was subsequently adjusted for maintenance of the target temperature. The average power uses for the solid and porous models were $15 \mathrm{~W}$ and $8 \mathrm{~W}$, respectively (Figure 7).

Temperature Distributions. The temperature-controlled $\left(90^{\circ} \mathrm{C}\right) \mathrm{FE}$ analyses were performed on both $3 \mathrm{~cm}$-indiameter and $5 \mathrm{~cm}$-in-diameter hepatic tumors under the solid and porous liver tissue conditions. Figures 8(a)-8(b), respectively, illustrate the degrees of tissue destruction for the solid and porous models with $3 \mathrm{~cm}$-in-diameter hepatic tumor. Figures $8(\mathrm{c})-8(\mathrm{~d})$, respectively, demonstrate the extents of tissue destruction for the solid and porous models in the case of $5 \mathrm{~cm}$-in-diameter hepatic tumor. In Figures $8(\mathrm{a})-8(\mathrm{~d})$, the temperature distributions are symmetric around $z$-axis. The areas with maximum temperatures ("hot zones") are those around the $4 \mathrm{~T}$ antenna opening (Figure 8). The lesion formation for all cases was of oculiform shape.

The ablation durations for complete destruction (100\%) of $3 \mathrm{~cm}$-in-diameter hepatic tumor (volume $=14.14 \mathrm{~cm}^{3}$ ) for the solid and porous models were, respectively, $135 \mathrm{~s}$ and $120 \mathrm{~s}$. In case of the $5 \mathrm{~cm}$-in-diameter hepatic tumor, the ablation duration for complete destruction in the porous model was $900 \mathrm{~s}$, while the maximum destruction in the solid model was a mere $93.60 \%$ even after 3600 s. In addition, the $4 \mathrm{~T}$ antenna caused damage to the normal liver tissue in the vicinity of the hepatic tumor (Figures 8(c)-8(d)). The volumes of normal tissue destruction for the liver with $5 \mathrm{~cm}$-in-diameter hepatic tumor were $8.19 \mathrm{~cm}^{3}$ and $33.56 \mathrm{~cm}^{3}$ for the solid and porous models, respectively.

The dimensions of ablation zone from FE simulations of porous model $(6.23 \mathrm{~cm} \times 5.28 \mathrm{~cm})$ are slightly larger than those of the in vitro experiments but, otherwise, exhibit similar characteristics (oculiform shape). Thus, we conclude that our FE analyses offer satisfying result in this study as FE 


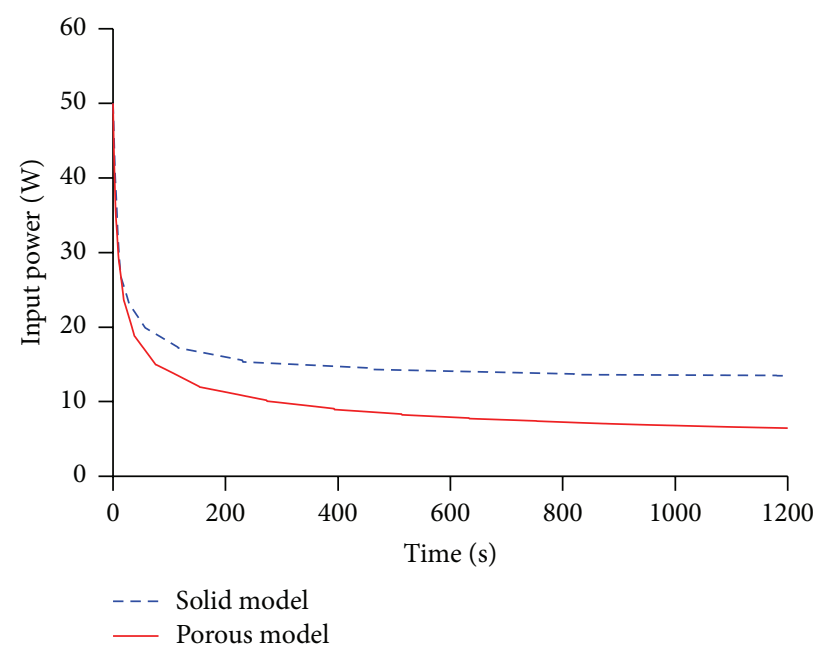

(a) Input power relative to time

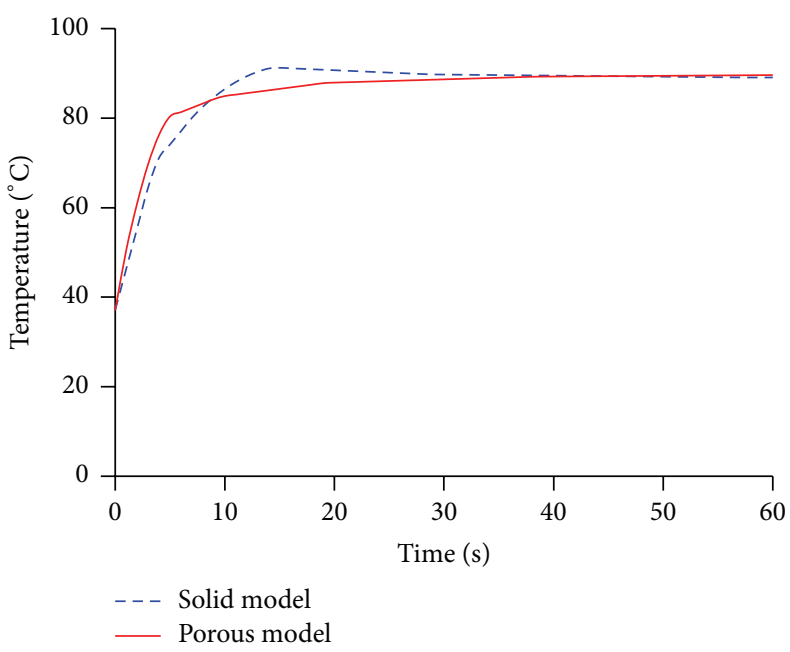

(b) Maximum temperature relative to time (start interval)

FIGURE 7: Microwave power delivery and maximum temperatures relative to time.

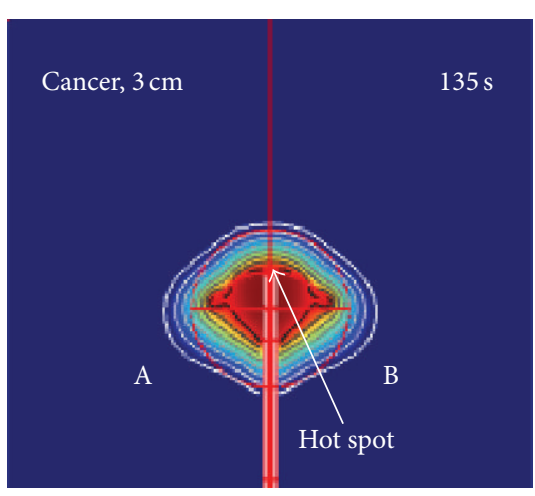

(a) Solid model, $y-z$ plane

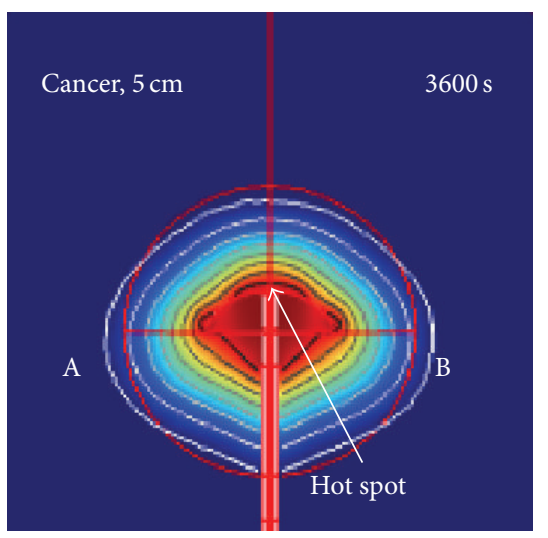

(c) Solid model, $y-z$ plane
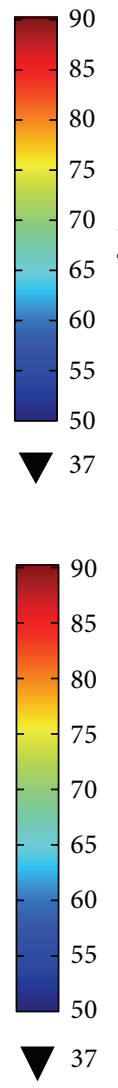

90
85
80
75
$70 \bigcirc 0$
65
60
55
50
37

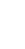

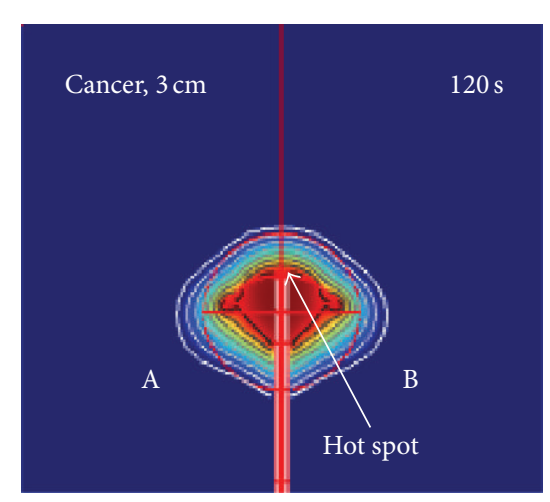

(b) Porous model, $y$ - $z$ plane

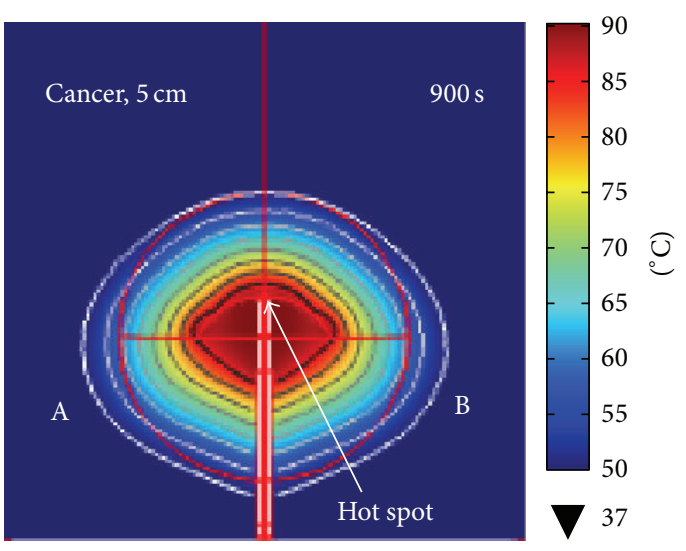

(d) Porous model, $y$ - $z$ plane

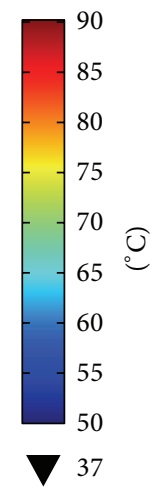




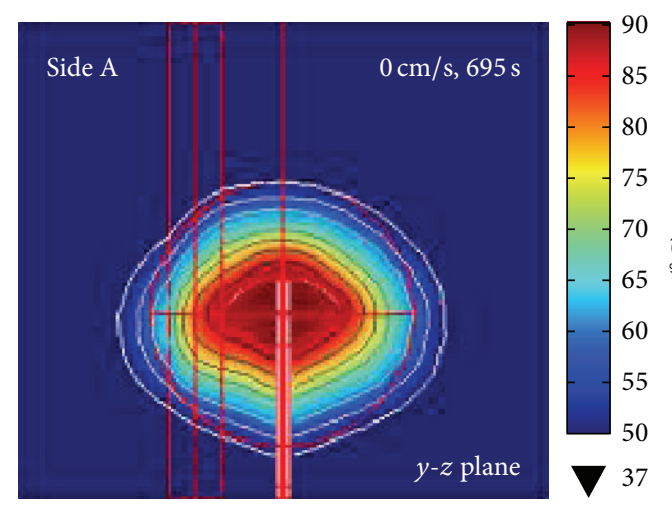

(a)

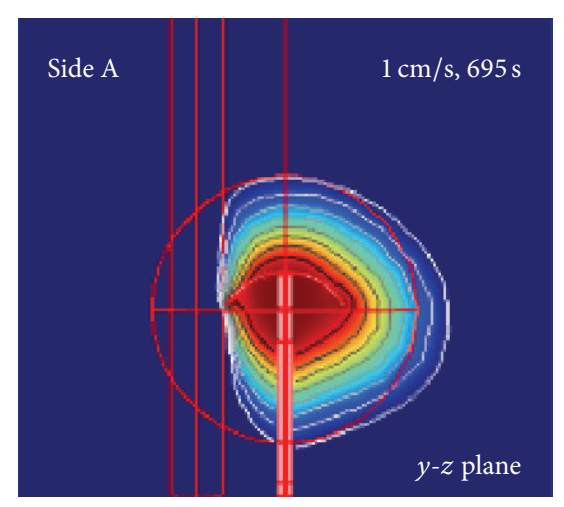

(c)

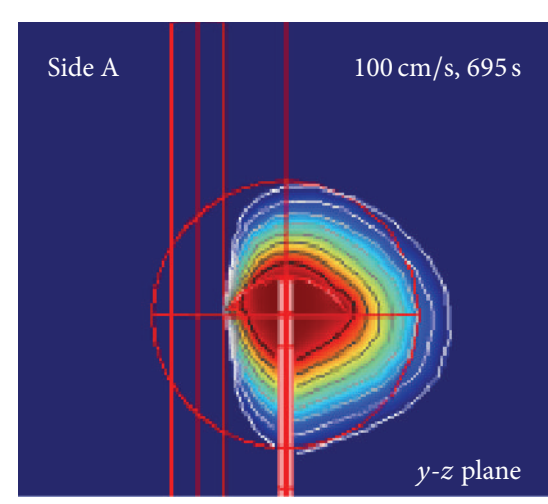

(e)

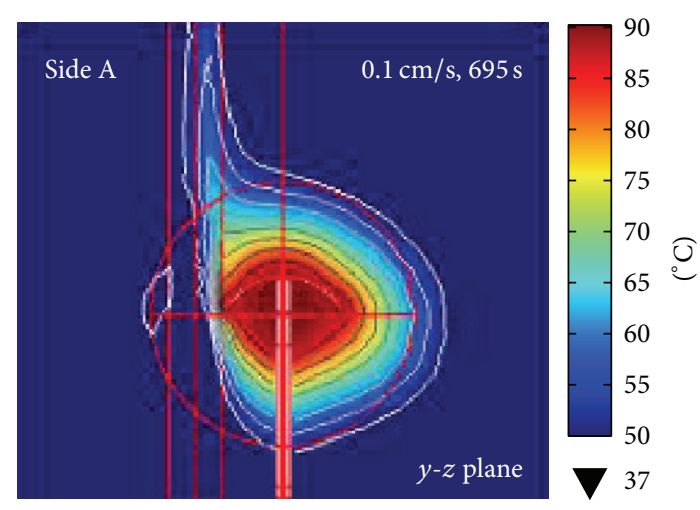

(b)

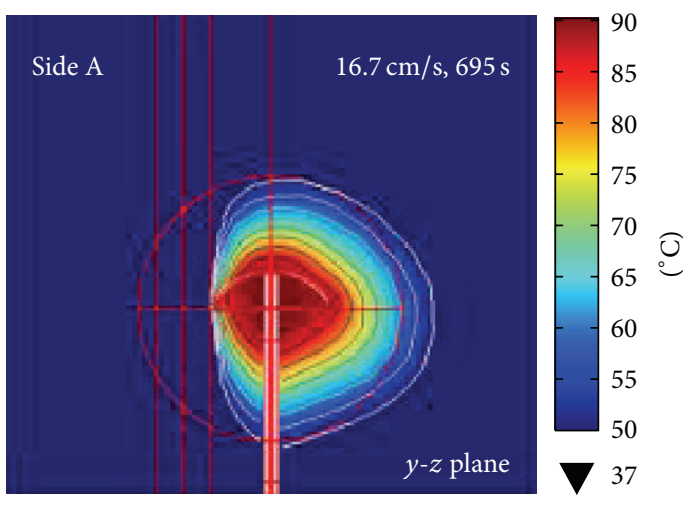

(d)

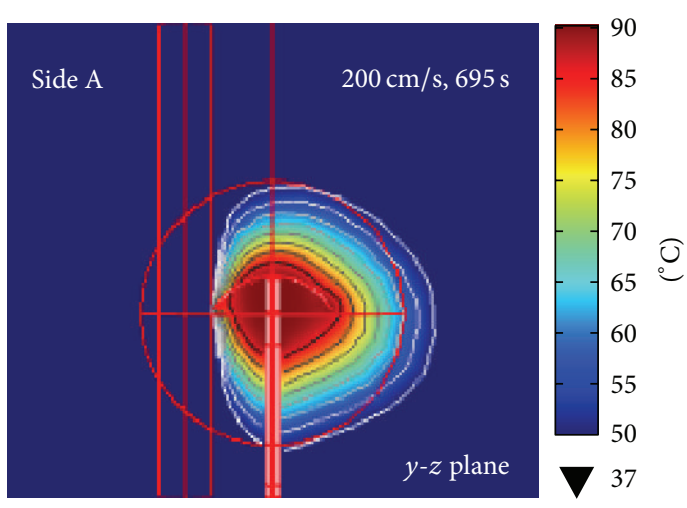

(f)

FIGURE 9: The cross sections (in the $y-z$ plane) of temperature distribution in the porous model with a 10 mm-in-diameter blood vessel in immediate contact with point $\mathrm{A}$ and parallel to the $4 \mathrm{~T}$ antenna (Figure $1(\mathrm{~b})$ ). The variations in the blood flow velocity range from (a) $0 \mathrm{~cm} / \mathrm{s}$, (b) $0.1 \mathrm{~cm} / \mathrm{s}$, (c) $1 \mathrm{~cm} / \mathrm{s}$, (d) $16.7 \mathrm{~cm} / \mathrm{s}$, (e) $100 \mathrm{~cm} / \mathrm{s}$, and (f) $200 \mathrm{~cm} / \mathrm{s}$.

upstream flow (Figure 9(b)). In the case of blood flow velocities below $5 \mathrm{~cm} / \mathrm{s}$, the temperatures along the vessel wall were above $37^{\circ} \mathrm{C}$. When the blood flow velocity was beyond $5 \mathrm{~cm} / \mathrm{s}$, the temperatures along the vessel wall remained at $37^{\circ} \mathrm{C}$ due to the high heat convection from blood flow and thereby more asymmetric temperature distributions. The high blood flow velocity resulted in smaller lesion dimensions as the lesion volume reduced from $62.87 \mathrm{~cm}^{3}(0 \mathrm{~cm} / \mathrm{s})$ to $56.63 \mathrm{~cm}^{3}(200 \mathrm{~cm} / \mathrm{s})$, as presented in Table 3 . In the presence of blood flow velocity, the ablation of hepatic tumor was below $100 \%$ (i.e., complete destruction) as the hepatic tissues surrounding the blood vessel remained unablated (Figures 9(b)-9(f)).

3.5. Effect of Blood Vessel Location on Lesion Formation and Tissue Deformation. The effects of varying blood vessel $(1 \mathrm{~cm}$ in diameter) locations (i.e., $0,0.8$, and 1.3 from point $\mathrm{A}$ ) on the lesion formation in the $5 \mathrm{~cm}$ hepatic cancer porous model at the constant $16.7 \mathrm{~cm} / \mathrm{s}$ flow velocity were determined by comparing the temperature distributions. In addition, the effects of thermal strain on tissue deformation were investigated. 
Temperature Distribution. Figure 10 illustrates the simulated temperature distributions on the $x-y$ and $y-z$ planes. Figures 10 (a)-10(c), respectively, illustrate the temperature distributions for the blood vessel locations at $0,0.8$, and $1.3 \mathrm{~cm}$. Contrary to the no blood vessel condition in which the lesion formation was symmetric, the lesion formations in the presence of blood vessel were asymmetric.

As presented in Table 3, the $4 \mathrm{~T}$ antenna can induce the MW power within the cancerous tissue to destroy the hepatic cancer. At the $0 \mathrm{~cm}$ blood vessel location, approximately $90.30 \%$ of the hepatic cancer was ablated. At the 0.8 and $1.3 \mathrm{~cm}$ locations, the destruction rates were, respectively, $96.27 \%$ and $99.55 \%$.

Total Displacement. Figure 11 shows the simulated maximum temperatures and total displacements of the liver tissue due to thermal strain relative to time in case of the $5 \mathrm{~cm}$ tumor porous model with $0 \mathrm{~cm}$ vessel location and $16.7 \mathrm{~cm} / \mathrm{s}$ blood flow velocity. The heating period of $\mathrm{MW}$ ablation and the subsequent cooling period were both $900 \mathrm{~s}$. The total displacements increased sharply immediately after the thermal treatment commenced. During the heating period, tissue displacements continuously increased and decreased due to tissue necrosis (stiffening) during the cooling period. The tissue displacement reached a peak of $5.9 \mathrm{~mm}$ at $90^{\circ} \mathrm{C}$. At the end of the cooling period, the temperature and displacements decreased to $56.3^{\circ} \mathrm{C}$ from originally $90^{\circ} \mathrm{C}$ (at termination of the heating period) and to $3.8 \mathrm{~mm}$ from $5.9 \mathrm{~mm}$.

\section{Discussions}

The aim of this research is to construct a most realistic FE model that represents the tissue transformation during and after MW liver ablation. In the FE analyses, the $2.45 \mathrm{GHz}$ $4 \mathrm{~T}$ antenna was deployed in ablating hepatic cancer in the porous liver tissue model and then the tissue temperature distributions were determined.

The effects of varying blood flow velocities on temperature distribution and tissue deformation (via total displacement) given that the blood vessel was in immediate contact $(0 \mathrm{~cm})$ with the $4 \mathrm{~T}$ antenna were determined. In addition, this research examined the impacts of varying blood vessel locations on the temperature distributions and tissue deformations.

The analyses of thermal destruction in the solid and porous models indicated different specific absorption rates (SAR) of the liver tissue during MW ablation. In the solid model analysis, the liver tissue was assumed to be homogeneous with no voids and in determination of the temperature distributions, only the EM properties, tissue thermal properties, and bioheat equation were used.

The porous liver tissue model was also assumed to be homogenous but contained small voids inside. The porous tissue is composed of tissue phase and interstitial space [27]. In the porous model analysis, in addition to the EM properties, tissue thermal properties, and bioheat equation, the tissue mechanical properties (i.e., porosity, viscosity, and Young's modulus, thermal expansion coefficient, and Poisson's ratio) are required to perform the thermal, electric, fluid flow, and structural analyses. By comparison, the simulated SAR and temperature were higher in the porous model than in the solid tissue, a phenomenon attributable to the higher electrical and thermal conductivities of fluid (i.e., blood) inside the porous tissue in relation to those of the tissue.

In the presence of the $1 \mathrm{~cm}$ blood vessel with high blood flow velocity, the temperature distribution pattern is asymmetric due to the loss of heat attributable to the blood flow, as seen in Figures 9-10 [25]. The flowing blood acts as a heat sink and thereby dissipates the thermal heat from the surrounding tissue. The percentage of hepatic tumor destruction and the shape of lesion formation are subject to the distance between the blood vessel and the $4 \mathrm{~T}$ antenna. The high blood flow velocity contributes to the convective cooling effect and thus a lower tissue temperature in the areas adjacent to the blood vessel.

According to [50], the thermal displacement initially increases rapidly. If the heating was sustained, the displacement would continue to increase but at a slower pace. It could be concluded that the change in the tissue displacement characteristics is indicative of the heat-induced structural changes in the hepatic tissue. Furthermore, the thermal displacement decreases over the course of cooling but does not return to the preheating state.

Major limitations of analyses in this study are simplified assumptions (e.g., simple steady flow of incompressible fluids) in the blood flow and energy equations (see (1)-(2)). In addition, we assumed that the conductor of the $4 \mathrm{~T}$ antenna was a perfect electric conductor. No phase change occurred within the liver tissue and no energy exchange through the outer surface of liver tissue was allowed. Future studies will address these limitations which will result in more accurate FE models.

\section{Conclusion}

This research has presented the 3D FE analyses of MW liver ablation using the $4 \mathrm{~T}$ antenna under various conditions. The FE analyses were first carried out with the solid and porous liver models with either $3 \mathrm{~cm}$-in-diameter tumor or $5 \mathrm{~cm}$-in-diameter tumor to investigate the specific absorption rates (SARs) along the $4 \mathrm{~T}$ antenna insertion depths and the temperature distributions. The porous liver tissue model with $5 \mathrm{~cm}$ tumor $\mathrm{MW}$-ablated using the proposed $4 \mathrm{~T}$ antenna was further examined with the introduction of the $1 \mathrm{~cm}$-indiameter blood vessel and variations of blood flow velocity $(0-200 \mathrm{~cm} / \mathrm{s})$ and blood vessel location $(0,0.8$, and $1.3 \mathrm{~cm}$ from a distal end of the $4 \mathrm{~T}$ antenna). In addition, the mechanical tissue deformation and liver tissue displacement were also observed. This model-based approach is economically sensible and medically safe as a first step for the development of simple tools for improved therapeutic effect. To verify the FE analysis results, more realistic in vitro and in vivo experiments will be part of our future research.

\section{Competing Interests}

The authors declare that they have no competing interests. 


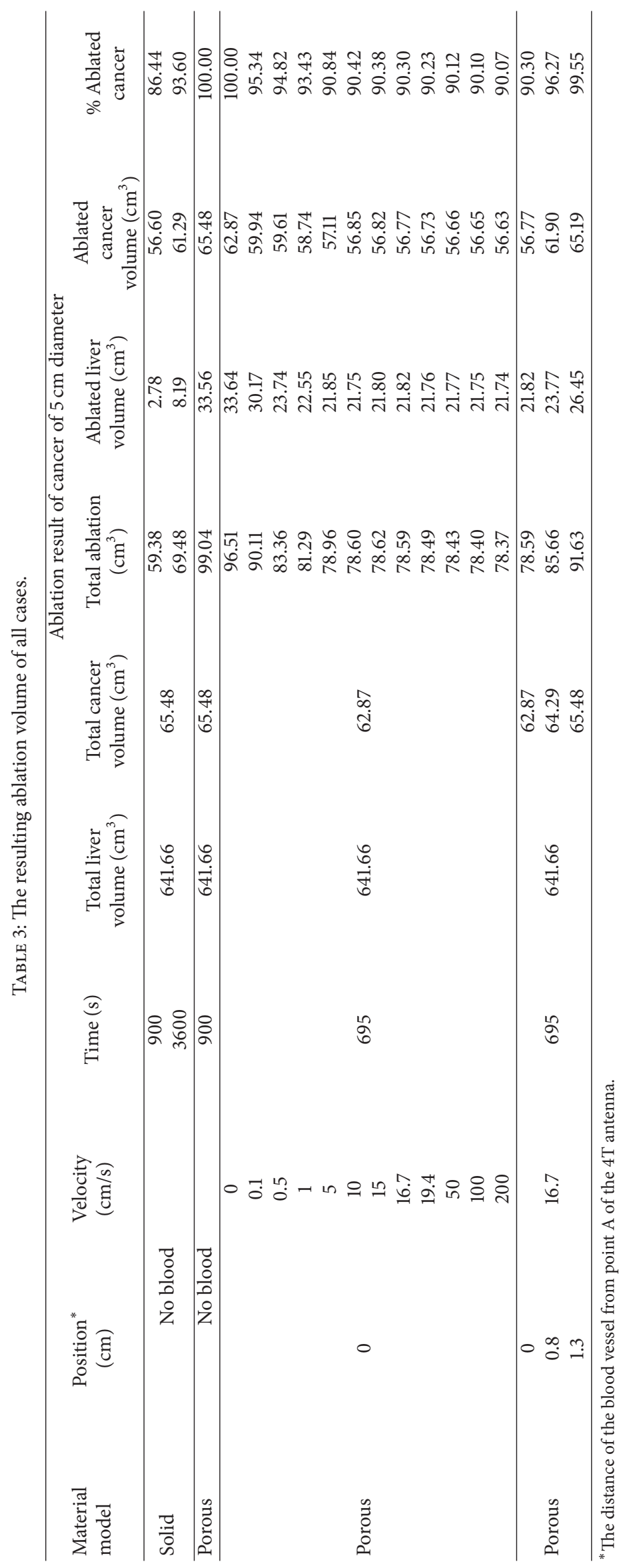



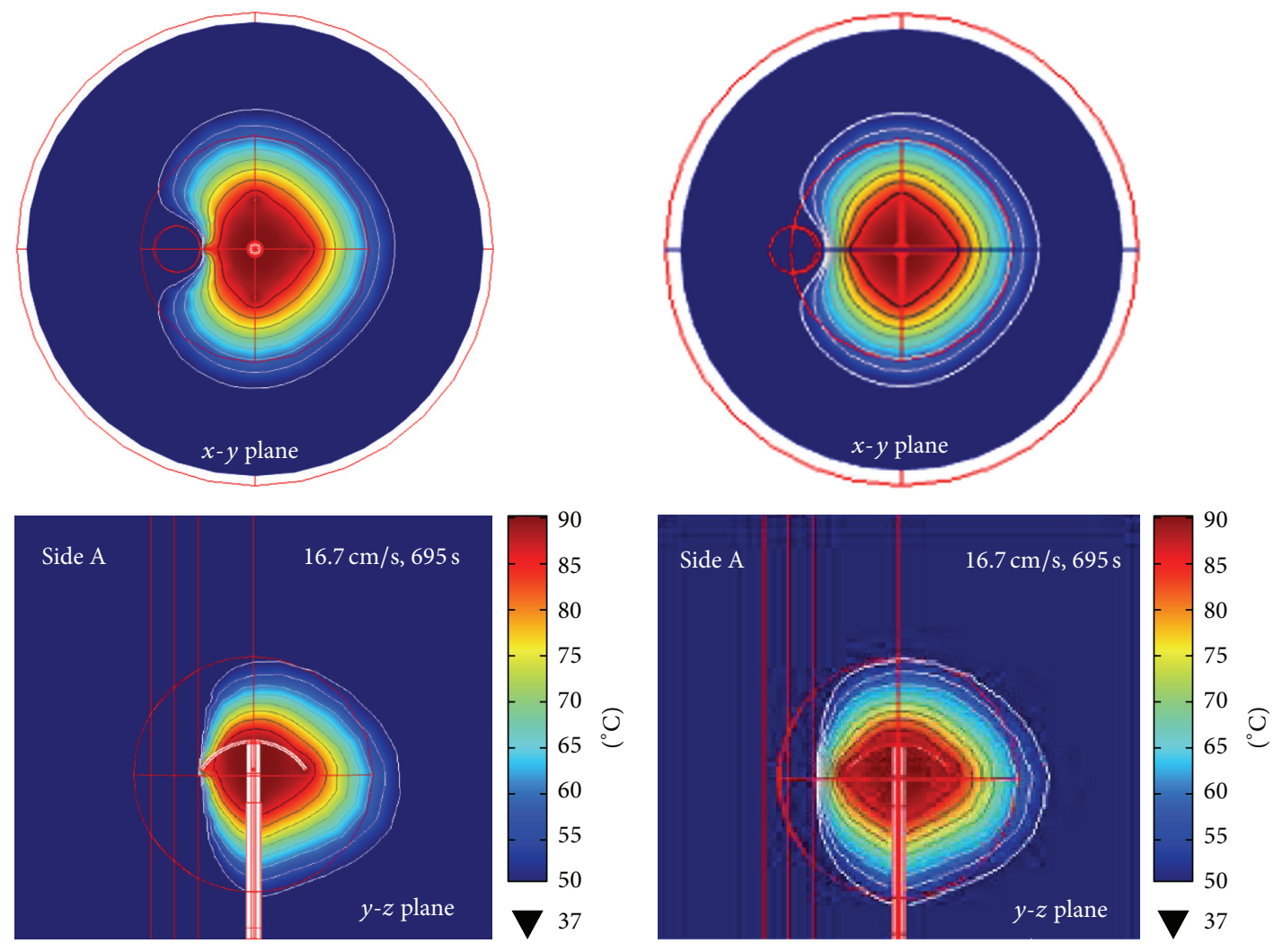

(a) $d=0 \mathrm{~cm}$

(b) $d=0.8 \mathrm{~cm}$
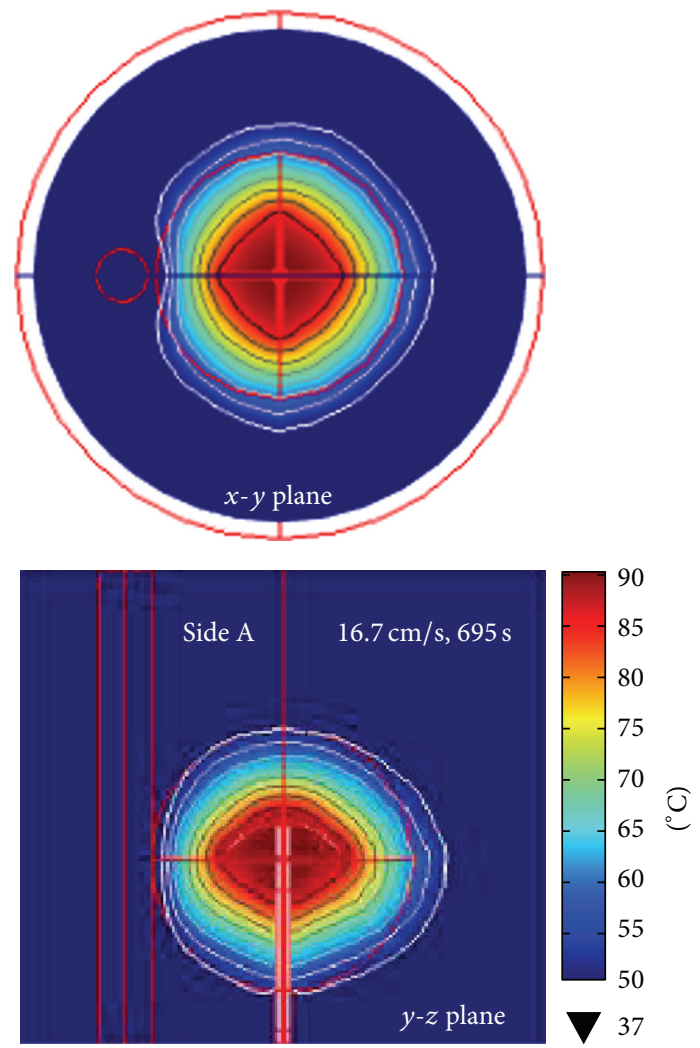

(c) $d=1.3 \mathrm{~cm}$

FIGURE 10: The cross sections (in the $x-y$ plane and $y-z$ plane) of temperature distribution in the $5 \mathrm{~cm}$-in-tumor porous model: (a) $1 \mathrm{~cm}$-indiameter blood vessel in immediate contact with point A and parallel to the $4 \mathrm{~T}$ antenna, (b) the blood vessel located $0.8 \mathrm{~cm}$ from point $\mathrm{A}$ and parallel to the antenna, and (c) the blood vessel located $1.3 \mathrm{~cm}$ from point $\mathrm{A}$ and parallel to the antenna. 


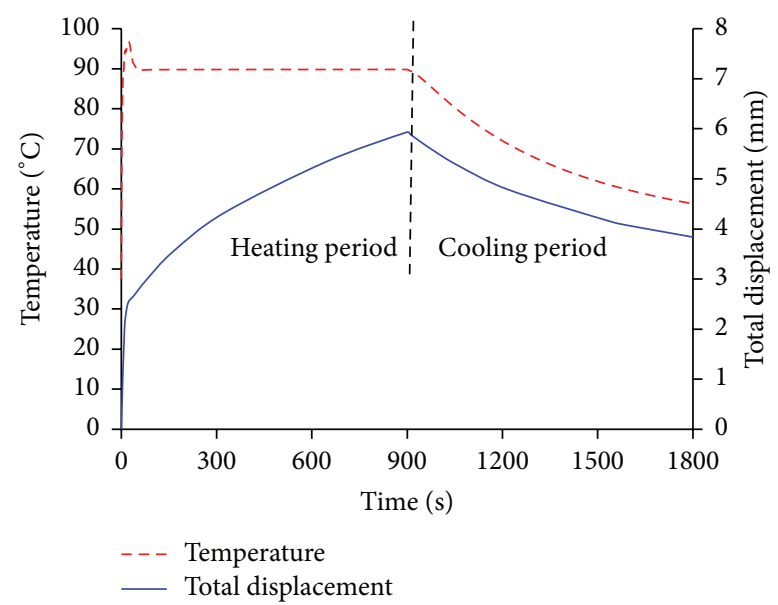

FIgURE 11: The depiction of the temperature and total displacement curve in the liver tissue due to thermal strain relative to time. The liver tissue is porous with $5 \mathrm{~cm}$ tumor with $0 \mathrm{~cm}$ vessel location and $16.7 \mathrm{~cm} / \mathrm{s}$ blood flow velocity.

\section{Acknowledgments}

This work is supported by King Mongkut's Institute of Technology Ladkrabang (KMITL) (KMITL Research Fund to Supan Tungjitkusolmun).

\section{References}

[1] C. J. Simon, D. E. Dupuy, and W. W. Mayo-Smith, "Microwave ablation: principles and applications," RadioGraphics, vol. 25, pp. S69-S83, 2005.

[2] T. F. Wood, D. M. Rose, M. Chung, D. P. Allegra, L. J. Foshag, and A. J. Bilchik, "Radiofrequency ablation of 231 unresectable hepatic tumors: indications, limitations, and complications," Annals of Surgical Oncology, vol. 7, no. 8, pp. 593-600, 2000.

[3] O. Seror, G. N'Kontchou, M. Ibraheem et al., "Large ( $\geq 5.0$ cm) HCCs: multipolar RF ablation with three internally cooled bipolar electrodes-initial experience in 26 patients," Radiology, vol. 248, no. 1, pp. 288-296, 2008.

[4] S. N. Goldberg, G. S. Gazelle, L. Solbiati, W. J. Rittman, and P. R. Mueller, "Radiofrequency tissue ablation: increased lesion diameter with a perfusion electrode," Academic Radiology, vol. 3, no. 8, pp. 636-644, 1996.

[5] L. W. Organ, "Electrophysiologic principles of radio frequency lesion making," Applied Neurophysiology, vol. 39, pp. 69-76, 1976.

[6] C. L. Brace, "Radiofrequency and microwave ablation of the liver, lung, kidney, and bone: what are the differences?" Current Problems in Diagnostic Radiology, vol. 38, no. 3, pp. 135-143, 2009.

[7] P. Prakash, M. C. Converse, J. G. Webster, and D. M. Mahvi, "Design optimization of coaxial antennas for hepatic microwave ablation using genetic algorithms," in Proceedings of the IEEE Antennas and Propagation Society International Symposium, pp. 1-4, San Diego, Calif, USA, July 2008.

[8] Y. Chang, W. Che, L. Yang, L. Yang, and G. Chen, "Experimental studies on microwave ablation in vitro animal tissues with microwave percutaneous coagulator," in Proceedings of the International Conference on Microwave and Millimeter Wave
Technology (ICMMT '08), vol. 4, pp. 1703-1706, IEEE, Nanjing, China, April 2008.

[9] M. F. J. Cepeda, A. Vera, and L. Leija, "Electromagnetic hyperthermia ablation devices for breast cancer: state of the art and challenges for the future," in Proceedings of the Pan American Health Care Exchanges (PAHCE '09), pp. 99-103, Mexico City, Mexico, March 2009.

[10] M. Cavagnaro, A. G. Tuzio, and S. Pisa, "The matching of microwave ablation antennas through a semi-analytic technique," in Proceedings of the 40th European Microwave Conference (EuMC '10), pp. 220-223, Paris, France, September 2010.

[11] P. Wang, C. L. Brace, M. C. Converse, and J. G. Webster, "Tumor boundary estimation through time-domain peaks monitoring: numerical predictions and experimental results in tissue-mimicking phantoms," IEEE Transactions on Biomedical Engineering, vol. 56, no. 11, pp. 2634-2641, 2009.

[12] P. Wang and C. L. Brace, "Tissue dielectric measurement using an interstitial dipole antenna," IEEE Transactions on Biomedical Engineering, vol. 59, no. 1, pp. 115-121, 2012.

[13] P. Prakash, M. C. Converse, J. G. Webster, and D. M. Mahvi, "An optimal sliding choke antenna for hepatic microwave ablation," IEEE Transactions on Biomedical Engineering, vol. 56, no. 10, pp. 2470-2476, 2009.

[14] S. Maini and A. Marwaha, "Comparison of coaxial choke and extended tip choke antenna for interstitial microwave ablation of HCC," in Proceedings of the World Congress on Information and Communication Technologies (WICT '11), pp. 841-845, IEEE, Mumbai, India, December 2011.

[15] C. L. Brace, P. F. Laeseke, D. W. Van Der Weide, and F. T. Lee Jr., "Microwave ablation with a triaxial antenna: results in ex vivo Bovine liver," IEEE Transactions on Microwave Theory and Techniques, vol. 53, no. 1, pp. 215-220, 2005.

[16] M. Cavagnaro, C. Amabile, P. Bernardi, S. Pisa, and N. Tosoratti, "A minimally invasive antenna for microwave ablation therapies: design, performances, and experimental assessment," IEEE Transactions on Biomedical Engineering, vol. 58, no. 4, pp. 949959, 2011.

[17] S. Kaurl and S. Maini, "Microwave Ablation therapy for the treatment of hepatocellular carcinoma using double slot interstitial antenna," International Journal of Research in Computer Applications and Robotics, vol. 2, no. 1, pp. 56-61, 2014.

[18] A. Karampatzakis, G. Tsanidis, S. Kuhn, E. Neufeld, N. Kuster, and T. Samaras, "Computational study of the performance of single applicators and antenna arrays used in liver microwave ablation," in Proceedings of the 7th European Conference on Antennas and Propagation (EuCAP '13), pp. 3112-3115, Gothenburg, Sweden, April 2013.

[19] R. Ortega-Palacios, A. Vera, L. Leija et al., "Microwave ablation coaxial antenna computational model slot antenna comparison," in Proceedings of the Pan American Health Care Exchanges (PAHCE '12), pp. 58-61, Miami, Fla, USA, March 2012.

[20] P. Phasukkit, S. Tungjitkusolmun, and A. Sanpanich, "Finite element analysis on phase shift effect of multi-antenna array alignment for microwave liver ablation," in Proceedings of the 2nd IEEE-EMBS Conference on Biomedical Engineering and Sciences (IECBES '12), pp. 326-329, IEEE, Langkawi, Malaysia, December 2012.

[21] C. J. Simon, D. E. Dupuy, D. A. Iannitti et al., "Intraoperative triple antenna hepatic microwave ablation," American Journal of Roentgenology, vol. 187, no. 4, pp. W333-W340, 2006.

[22] A. S. Wright, F. T. Lee Jr., and D. M. Mahvi, "Hepatic microwave ablation with multiple antennae results in synergistically larger 
zones of coagulation necrosis," Annals of Surgical Oncology, vol. 10, no. 3, pp. 275-283, 2003.

[23] A. S. Wright, L. A. Sampson, T. F. Warner, D. M. Mahvi, and F. T. Lee Jr., "Radiofrequency versus microwave ablation in a hepatic porcine model," Radiology, vol. 236, no. 1, pp. 132-139, 2005.

[24] A. U. Hines-Peralta, N. Pirani, P. Clegg et al., "Microwave ablation: results with a $2.45-\mathrm{GHz}$ applicator in ex vivo bovine and in vivo porcine liver," Radiology, vol. 239, no. 1, pp. 94-102, 2006.

[25] S. Tungjitkusolmun, S. T. Staelin, D. Haemmerich et al., "Threedimensional finite-element analyses for radio-frequency hepatic tumor ablation," IEEE Transactions on Biomedical Engineering, vol. 49, no. 1, pp. 3-9, 2002.

[26] A. J. Bilchik, T. F. Wood, and D. P. Allegra, "Radiofrequency ablation of unresectable hepatic malignancies: lessons learned," The Oncologist, vol. 6, no. 1, pp. 24-33, 2001.

[27] A. Nakayama and F. Kuwahara, "A general bioheat transfer model based on the theory of porous media," International Journal of Heat and Mass Transfer, vol. 51, no. 11-12, pp. 31903199, 2008.

[28] H. H. Pennes, "Analysis of tissue and arterial blood temperatures in the resting human forearm," Journal of applied physiology, vol. 1, no. 2, pp. 93-122, 1948.

[29] A.-R. A. Khaled and K. Vafai, "The role of porous media in modeling flow and heat transfer in biological tissues," International Journal of Heat and Mass Transfer, vol. 46, no. 26, pp. 49895003, 2003.

[30] W. Shen, J. Zhang, and F. Yang, "Modeling and numerical simulation of bioheat transfer and biomechanics in soft tissue," Mathematical and Computer Modelling, vol. 41, no. 11-12, pp. 1251-1265, 2005.

[31] F. Xu, T. Wen, T. J. Lu, and K. A. Seffen, "Skin biothermomechanics for medical treatments," Journal of the Mechanical Behavior of Biomedical Materials, vol. 1, no. 2, pp. 172-187, 2008.

[32] D. K. Cheng, Field and Wave Electromagnetics, Addison-Wesley, 2nd edition, 1991.

[33] J. Jin, The Finite Element Method in Electromagnetics, WileyIEEE Press, 2nd edition, 2002.

[34] R. J. Keeet, M. E. Coltrin, and P. Glarborg, Chemically Reacting Flow: Theory and Practice, John Wiley \& Sons, New York, NY, USA, 2003.

[35] K. Vafai and C. L. Tien, "Boundary and inertia effects on flow and heat transfer in porous media," International Journal of Heat and Mass Transfer, vol. 24, no. 2, pp. 195-203, 1981.

[36] G. K. Batchelor, An Introduction to Fluid Dynamics, Cambridge University Press, Cambridge, UK, 1967.

[37] Y. Zhang, "Generalized dual-phase lag bioheat equations based on nonequilibrium heat transfer in living biological tissues," International Journal of Heat and Mass Transfer, vol. 52, no. 2122, pp. 4829-4834, 2009.

[38] T. Peng, D. P. O’Neill, and S. J. Payne, “A two-equation coupled system for determination of liver tissue temperature during thermal ablation," International Journal of Heat and Mass Transfer, vol. 54, no. 9-10, pp. 2100-2109, 2011.

[39] Y. Rabin and A. Shitzer, "Numerical solution of the multidimensional freezing problem during cryosurgery," Journal of Biomechanical Engineering, vol. 120, no. 1, pp. 32-37, 1998.

[40] D. Roylance, Mechanical Properties of Materials, Massachusetts Institute of Technology, Cambridge, Mass, USA, 2008.

[41] P. Rattanadecho and P. Keangin, "Numerical study of heat transfer and blood flow in two-layered porous liver tissue during microwave ablation process using single and double slot antenna," International Journal of Heat and Mass Transfer, vol. 58, no. 1-2, pp. 457-470, 2013.

[42] S. Whitaker, "Fluid motion in porous media," Industrial \& Engineering Chemistry, vol. 61, no. 12, pp. 14-28, 1969.

[43] J. C. Slattery, "Single-phase flow through porous media," AIChE Journal, vol. 15, no. 6, pp. 866-872, 1969.

[44] M. Zoli, D. Magalotti, G. Bianchi et al., "Total and functional hepatic blood flow decrease in parallel with ageing," Age and Ageing, vol. 28, no. 1, pp. 29-34, 1999.

[45] D. Yang, M. C. Converse, D. M. Mahvi, and J. G. Webster, "Expanding the bioheat equation to include tissue internal water evaporation during heating," IEEE Transactions on Biomedical Engineering, vol. 54, no. 8, pp. 1382-1388, 2007.

[46] P. Keangin, K. Vafai, and P. Rattanadecho, "Electromagnetic field effects on biological materials," International Journal of Heat and Mass Transfer, vol. 65, pp. 389-399, 2013.

[47] M. Daniels, Temperature estimation with ultrasound [Ph.D. dissertation], Department of Physics, University of WisconsinMadison, 2008.

[48] P. Keangin, T. Wessapan, and P. Rattanadecho, "Analysis of heat transfer in deformed liver cancer modeling treated using a microwave coaxial antenna," Applied Thermal Engineering, vol. 31, no. 16, pp. 3243-3254, 2011.

[49] S. Tungjitkusolmun, E. J. Woo, H. Cao, J. Z. Tsai, V. R. Vorperian, and J. G. Webster, "Thermal-electrical finite element modelling for radio frequency cardiac ablation: effects of changes in myocardial properties," Medical and Biological Engineering and Computing, vol. 38, no. 5, pp. 562-568, 2000.

[50] C. Maleke and E. E. Konofagou, "Harmonic motion imaging for focused ultrasound (HMIFU): a fully integrated technique for sonication and monitoring of thermal ablation in tissues," Physics in Medicine and Biology, vol. 53, no. 6, pp. 1773-1793, 2008. 


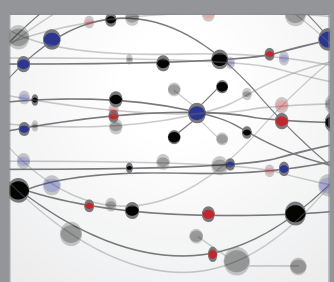

The Scientific World Journal
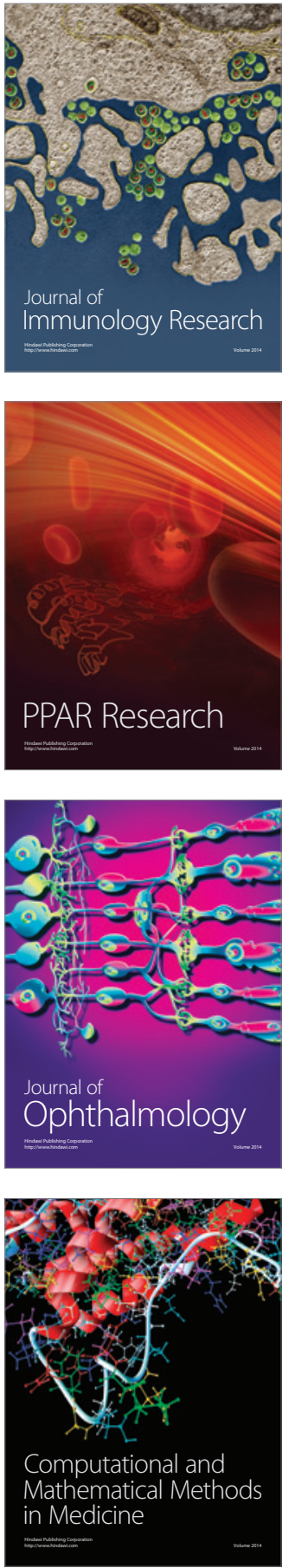

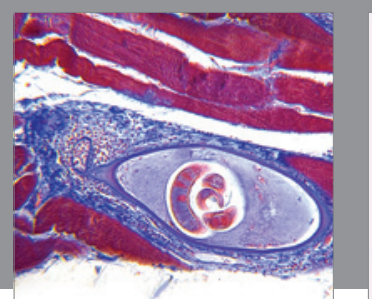

Gastroenterology Research and Practice

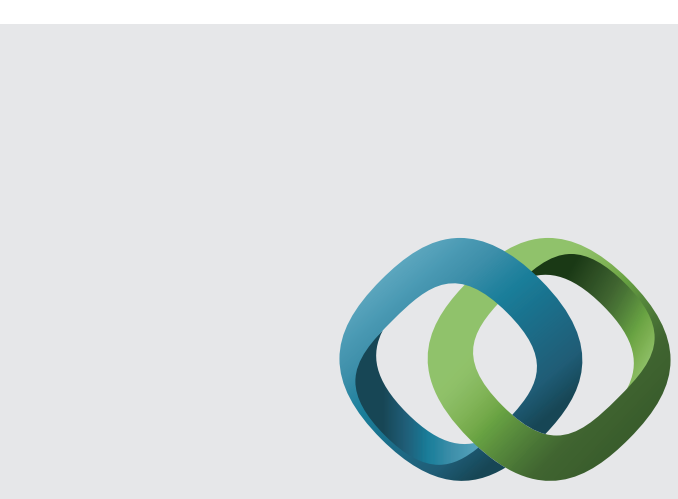

\section{Hindawi}

Submit your manuscripts at

http://www.hindawi.com
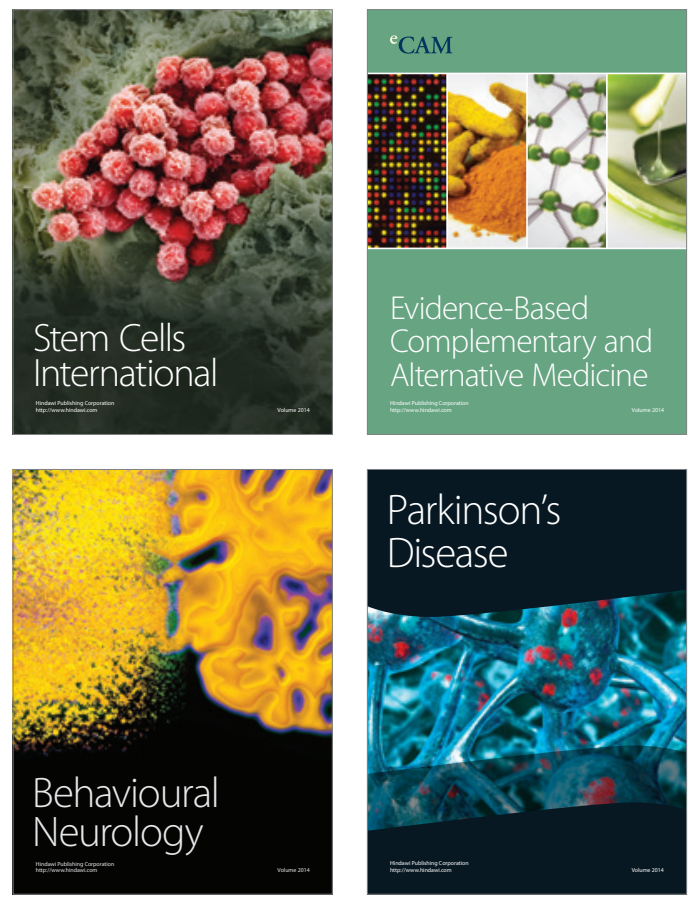
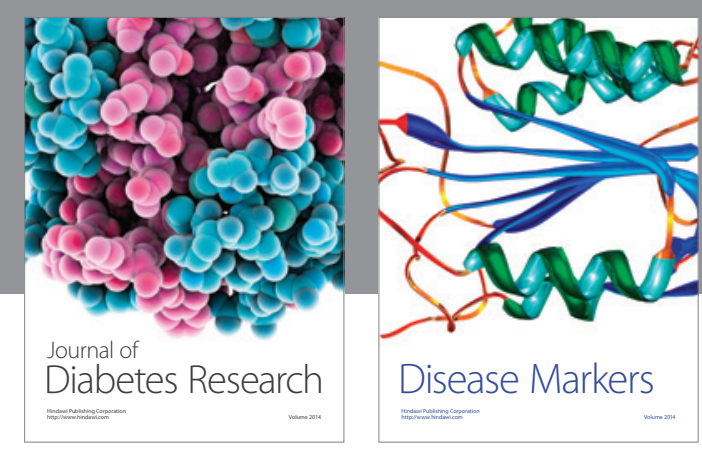

Disease Markers
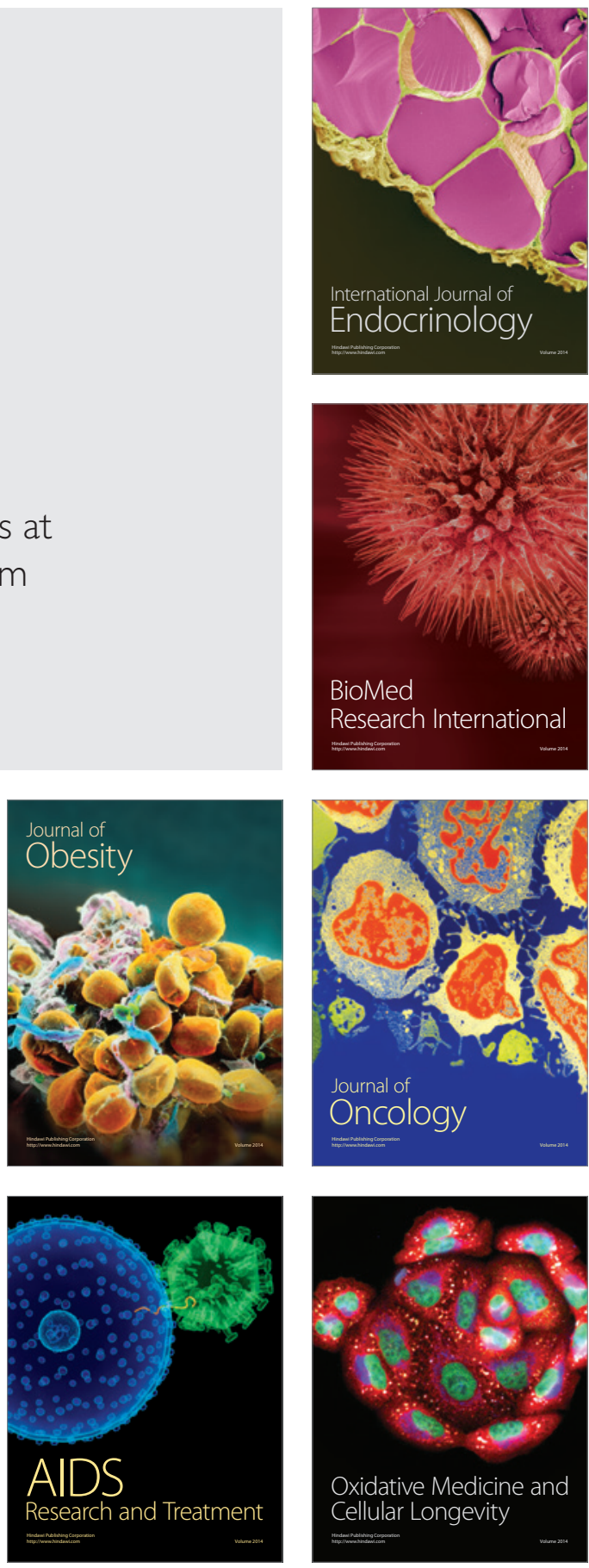